\title{
Immunocytochemical localization and functional determination of phytoene desaturase in photoautotrophic prokaryotes
}

\author{
Aurelio Serrano, $\uparrow$ Patricia Gimenez, $\dagger$ Arno Schmidt and Gerhard Sandmann* \\ Lehrstuhl für Physiologie und Biochemie der Pflanzen, Universität Konstanz, Postfach 5560, \\ D-7750 Konstanz, Germany
}

(Received 19 February 1990; revised 19 June 1990; accepted 21 August 1990)

\begin{abstract}
The in situ location of phytoene desaturase, an enzyme in the carotenoid biosynthetic pathway, has been investigated in the photosynthetic organisms Rhodobacter capsulatus SB 1003, Synechocystis PCC 6714, and Anabaena variabilis ATCC 29413. A post-embedding immunogold electron microscopy procedure using a polyclonal antibody against a phytoene desaturase fusion protein was employed. For all three species most of the gold particles (about $85 \%$ in the case of Anabaena and Synechocystis) were associated with the photosynthetic membranes. Other parts of the cells were only randomly and not significantly labelled. When the anti-phytoene desaturase antibody was omitted, or when pre-immune serum was used, no gold deposition was observed. In vitro phytoene desaturase reactions, especially with purified thylakoid membranes from Synechocystis, confirmed the nature of phytoene desaturase as an integral protein of the thylakoid membrane.
\end{abstract}

\section{Introduction}

Phytoene desaturase is a key enzyme in the biosynthetic route of carotenoids (Bramley, 1985). It converts phytoene into $\zeta$-carotene and shows feedback inhibition by subsequent carotenes in the pathway (Bramley \& Davies, 1976; Sandmann \& Kowalczyk, 1989); it is the target for various commercial herbicides (Sandmann \& Böger, 1989). Biochemical characterization of this enzyme from photosynthetic organisms has been reported (Clarke et al., 1982; Sandmann \& Kowalczyk, 1989), 'but its purification has not yet been achieved. Nevertheless, the recent progress in the molecular biology of several carotenogenic enzymes, including phytoene desaturase (Armstrong et al., 1989; Bartley \& Scolnik, 1989), made it possible to construct a fusion gene with the lac $Z$ gene and a $921 \mathrm{bp}$ fragment of the phytoene desaturase gene. Expression in Escherichia coli resulted in a fusion protein which was employed to raise polyclonal antibodies. These antibodies inhibit phytoene desaturation and cross-react in Western blots with phytoene desaturase from a photosynthetic bacterium, from a cyanobacterium, and from higher plants (Schmidt et al., 1989).

† Present address: Instituto de Bioquímica Vegetal y Fotosíntesis, CSIC, Universidad de Sevilla, Apdo. 1113, E-41080 Sevilla, Spain.

\footnotetext{
Abbreviations: GGPP, geranylgeranyl pyrophosphate; PBS, phosphate buffered saline ( $20 \mathrm{~mm}$-sodium phosphate, $0.9 \% \mathrm{NaCl}$, pH 7.4).
}

This antibody preparation and immunocytochemical methods were used in the present investigation to localize phytoene desaturase in the photosynthetic bacterium Rhodobacter capsulatus SB 1003, and in the unicellular and the filamentous cyanobacteria Synechocystis PCC 6714 and Anabaena variabilis ATCC 29413, respectively. Phytoene desaturase activities were also determined in all three organisms and the results obtained by immunogold-labelling studies were confirmed in Synechocystis by in vitro reactions with purified thylakoids.

\section{Methods}

Organisms and growth. Culture conditions for Synechocystis PCC 6714 and Anabaena variabilis ATCC 29413 were as used previously for other cyanobacteria (Clarke et al., 1982), and those for Rhodobacter capsulatus SB 1003 were as described by Marrs (1981). After $2 \mathrm{~d}$ of growth, cells were harvested by centrifugation for use in in vitro studies and fixation. The Fusarium mutant SG4 (from Departamento de Genetica, Universidad de Sevilla, Spain), in which phytoene formation is blocked, was grown in $2.4 \%(\mathrm{w} / \mathrm{v})$ potato-dextrose broth for $5 \mathrm{~d}$.

In vitro assays. Cell-free carotenogenesis by the photosynthetic prokaryotes was carried out in a coupled system using Fusarium SG4 extracts as a source of $\left[{ }^{14} \mathrm{C}\right]$ geranylgeranyl pyrophosphate (GGPP, synthesized from $\mathrm{R}-\left[2-{ }^{14} \mathrm{C}\right]$ mevalonic acid), following the conversion of GGPP into the subsequent carotenes. The details of this assay with membanes from the cyanobacteria are given by Sandmann \& Kowalczyk (1989). In the case of Synechocystis, thylakoids were 
purified from a French-press homogenate by centrifugation on a sucrose gradient and the purity of the preparation was determined by its absorption spectrum, as described by Murata \& Omata (1988). The membrane preparation and in vitro assay for Rhodobacter were the same as for cyanobacteria. However, the carotenoid extract was evaporated to dryness, resuspended in toluene and passed through a silica column before application to the HPLC column. The column retains polar compounds which might interfere with the detection of $\zeta$-carotene.

Fixation, embedding and immunocytochemical labelling. The cells were fixed with $2.5 \%(\mathrm{w} / \mathrm{v})$ glutaraldehyde in $0.1 \mathrm{M}$-sodium cacodylate

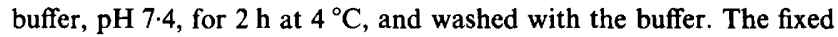
material was subsequently dehydrated in ethanol $(30-100 \%)$ and twice in propylene oxide. Samples were embedded in Epon 812 (Polysciences, USA). Ultrathin sections were obtained on a Reichert ultramicrotome using glass knives and placed on gold or nickel grids (200 mesh) covered with carbon-coated Formvar film. The grids were then incubated with the following solutions by floating them (specimen-side down) on the surface of small drops and transferring them from one drop to another with forceps. The sequence of the incubations was: $10 \mathrm{~min}$ distilled water; $10 \mathrm{~min} 10 \%(\mathrm{v} / \mathrm{v}) \mathrm{H}_{2} \mathrm{O}_{2}$ in distilled water; $10 \mathrm{~min} \mathrm{NaBH}_{4}$ ( $3 \mathrm{mg} \mathrm{ml}^{-1}$ in distilled water); $10 \mathrm{~min}$ $50 \mathrm{~mm}$-glycine in PBS; $5 \mathrm{~min} 20 \mathrm{~mm}-\mathrm{NH}_{4} \mathrm{Cl}$ in PBS; $1 \mathrm{~h}$ PBS supplemented with $5 \%(\mathrm{v} / \mathrm{v})$ newborn calf serum, $0 \cdot 2 \%(\mathrm{v} / \mathrm{v})$ Tween 20 and $0.5 \mathrm{M}-\mathrm{NaCl}$ (PBS/STN); $2 \mathrm{~h}$ specific antiserum diluted $1: 10$ or $1: 20$ in PBS/STN, or only PBS/STN, in a moist chamber with shaking; 5 min washing in PBS/STN and overnight in the same buffer at $4{ }^{\circ} \mathrm{C}$; $2 \mathrm{~h}$ goat anti-rabbit IgG conjugated with $10 \mathrm{~nm}$ diameter colloidal gold (Janssen Pharmaceutica, Beerse, Belgium), diluted $1: 20$ in PBS/STN in a moist chamber with shaking; $3 \times 10 \mathrm{~min}$ washing in PBS supplemented with Tween 20 and $\mathrm{NaCl} ; 10$ min distilled water; $2 \mathrm{~h} 4 \%$ $(\mathrm{w} / \mathrm{v})$ uranyl acetate in water; $5 \mathrm{~min}$ alkaline lead citrate solution (Reynolds, 1963). The sections were examined with a Zeiss 9S TEM at calibrated magnifications and at an acceleration voltage of $60 \mathrm{kV}$.

The distance from the antigen to the gold marker - estimated from the size of the antigen-antibody complex (Rohde et al., 1988) - was considered to be $40 \mathrm{~nm}$, and was used as the maximal tolerable distance of a gold particle to be counted as a label for a given cell structure.

\section{Results and Discussion}

The antibody raised in rabbits against the $\beta$-galactosidase-phytoene desaturase fusion protein has recently been characterized (Schmidt et al., 1989). It recognized a single protein of molecular mass $65 \mathrm{kDa}$ in Western blots of SDS polyacrylamide gels after electrophoresis of detergent-treated cell extracts from Rhodobacter and Synechocystis. Since $\beta$-galactosidase is absent from Rhodobacter, cyanobacteria and higher plants, the antibody against the phytoene desaturase fusion protein is suitable for immunodetection of this enzyme on ultrathin sections. We have employed this antibody preparation to investigate the cellular location of phytoene desaturase in photosynthetic prokaryotes using the antibody-gold technique in a post-embedding immunoelectron microscopy procedure. It has recently been demonstrated that the antigenicity of cyanobacterial tissue is retained when using conventional Epon embedding (Bergman et al., 1985), and immunogold labelling has been successfully used for cyanobacterial cells (Bergman et al., 1985; Hawthornthwaite et al., 1985).

Typical electron micrographs of phytoene desaturase localization using rabbit anti-fusion protein antibodies and colloidal gold-conjugated anti-rabbit IgG are shown in Fig. 1. The ultrathin sections $(a)$ and $(b)$ are from the photosynthetic bacterium Rhodobacter, whereas $(c)$ and (d) are from the unicellular cyanobacterium Synechocystis. In both organisms, gold labelling of phytoene desaturase (Fig. $1 a, c$ ) resulted in the association of gold particles with the photosynthetic membranes, which in the case of Synechocystis are intracellular thylakoids. Very few gold particles were located, however, in the cytoplasm and no non-specific background labelling was observed outside the cells.

In the case of Rhodobacter it cannot be ruled out that some gold particles located in the cytoplasm could be associated with the intracellular system of membranebounded vesicles described for many purple bacteria. This seems, however, rather unlikely in our case because the Rhodobacter cultures were grown under such environmental conditions, i.e. aerobic growth under illumination, which not only induce intense carotenoid biosynthesis but also dramatically reduce the abundance of intracellular vesicles. In fact, intracellular membranes are not discernible in our Rhodobacter preparations.

In control experiments (Fig. $1 b, d$ ), when the antiphytoene desaturase antibody was omitted, or when preimmune serum was used, no gold particles were found associated with the cells, thus demonstrating the specificity of the phytoene desaturase antibody. A similar gold-labelling experiment with the phytoene desaturase antibody for the filamentous cyanobacterium Anabaena variabilis is shown in Fig. 2. The label was preferentially located over the intracellular thylakoid membranes (Fig.

Table 1. Distribution of colloidal gold particles in the location of phytoene dehydrogenase by immunochemistry

For each species 10 individual cells were examined; 314,773 and 1133 gold particles were counted in the case of Rhodobacter, Synechocystis and Anabaena, respectively.

\begin{tabular}{lccc}
\hline \hline & \multicolumn{2}{c}{ Percentage of gold particles $( \pm \mathrm{SD})$ in: } \\
\cline { 2 - 4 } & $\begin{array}{c}\text { Cytoplasmic } \\
\text { membrane } \\
\text { region* }\end{array}$ & $\begin{array}{c}\text { Thylakoid } \\
\text { membranes }\end{array}$ & Cytoplasm \\
\hline $\begin{array}{l}\text { Rhodobacter capsulatus } \\
\text { SB 1003 }\end{array}$ & $78 \pm 5$ & - & $22 \pm 5$ \\
$\begin{array}{l}\text { Synechocystis PCC 6714 } \\
\text { Anabaena variabilis }\end{array}$ & $9 \pm 3$ & $85 \pm 6$ & $6 \pm 3$ \\
ATCC 29413 & $9 \pm 4$ & $84 \pm 5$ & $7 \pm 4$ \\
\hline \hline
\end{tabular}

* Includes cytoplasmic membrane, periplasmic space and outer membrane. 

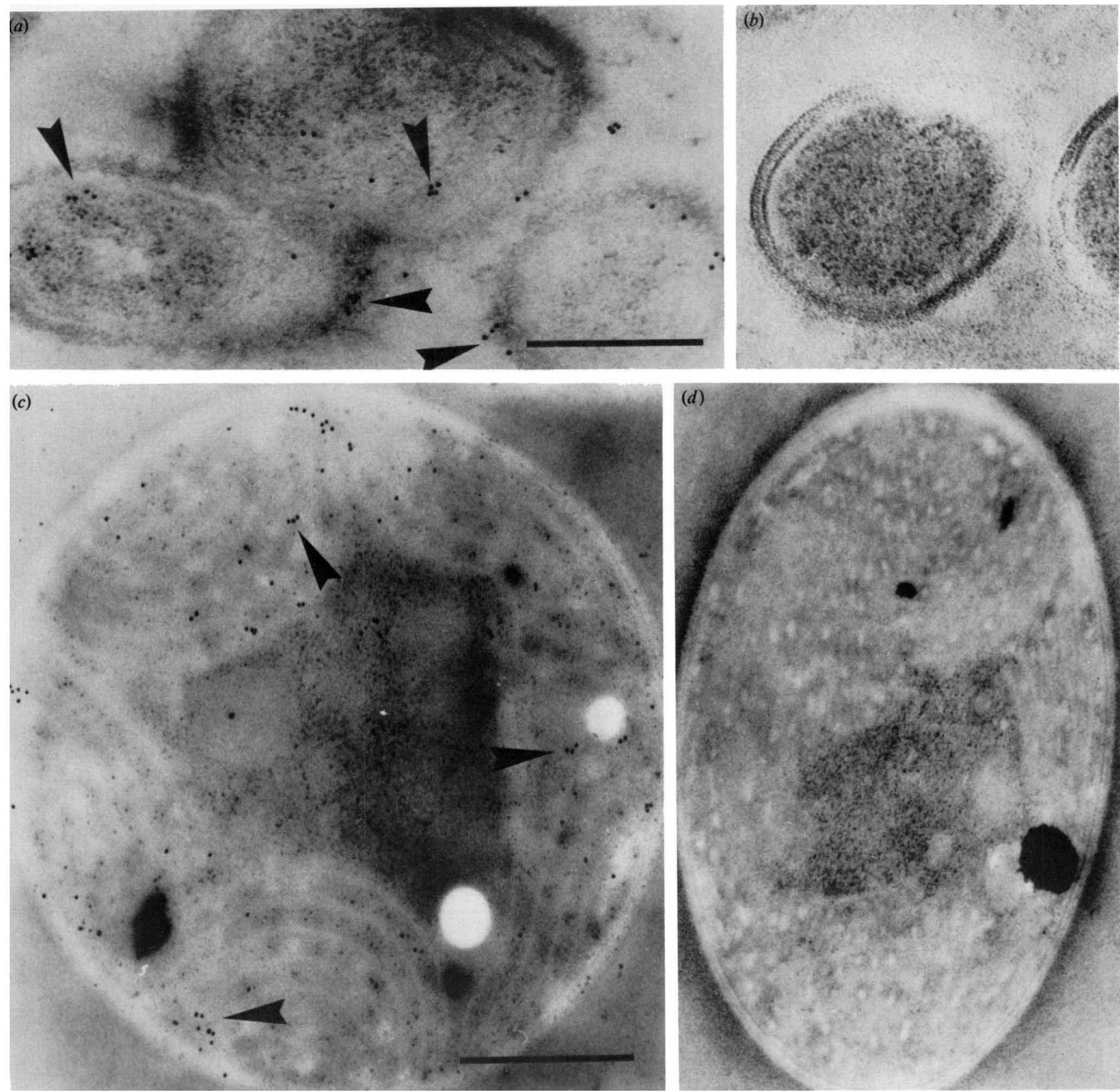

Fig. 1. Immunocytochemical localization of phytoene desaturase in Rhodobacter capsulatus $(a, b)$ and Synechocystis PCC 6714 (c, $d$ ) cells. Note that in both organisms the majority of the gold particles are located in the photosynthetic membranes (arrows in $a$ and $c$ ). No significant labelling is observed in control experiments $(b, d)$. Bars, $0.5 \mu \mathrm{m}$ (all pictures have the same magnification).

$2 a$ ) and again non-specific labelling was negligible in the control experiment (Fig. 2b). Statistical data on the distribution of gold labelling particles in immunolabelling experiments are shown in Table 1 . Most of the gold particles, about $80 \%$, were observed in the photosynthetic membranes in the species of photosynthetic prokaryotes studied.
The immunochemical results were substantiated by in vitro assays (Table 2). For both cyanobacteria, which, in contrast to Rhodobacter, form cyclic carotenes, conversion of $\left[{ }^{14} \mathrm{C}\right] \mathrm{GGPP}$ in the carotene pathway to phytoene, $\zeta$-carotene and $\beta$-carotene was observed. Other carotenes were not labelled. In the case of Rhodobacter, which forms hydroxylated acyclic carotenoids from neurospor- 

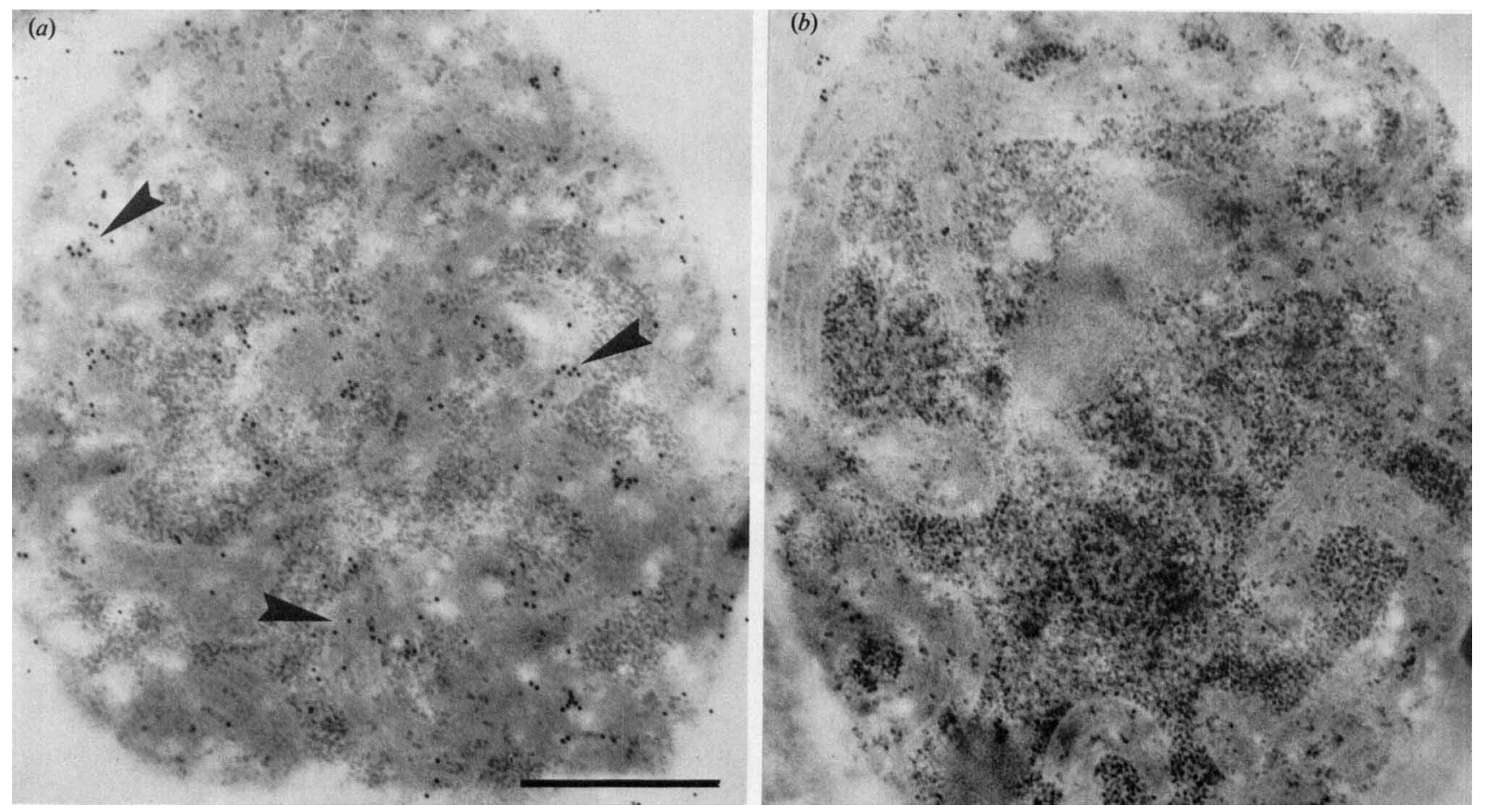

Fig. 2. Immunocytochemical localization of phytoene desaturase in vegetative cells of Anabaena variabilis (a). Note that most of the gold particles appear associated with thylakoids (arrows). No significant labelling is observed in control experiments using preimmune serum $(b)$. Bar, $0 \cdot 5 \mu \mathrm{m}$.

Table 2. In vitro carotene formation from $\left[{ }^{14} C\right] G G P P$

For details see Methods; $3 \times 10^{4}$ d.p.m. $\left[{ }^{14} \mathrm{C}\right]$ GGPP was used as substrate : the results represent typical data taken from a set of experiments; the conversion rate of phytoene varied in the range of $\pm 10 \%$.

\begin{tabular}{|c|c|c|c|c|}
\hline \multirow[b]{2}{*}{ Organism } & \multicolumn{3}{|c|}{ Radioactivity (d.p.m.) incorporated into: } & \multirow{2}{*}{$\begin{array}{l}\text { Percentage } \\
\text { conversion } \\
\text { of phytoene }\end{array}$} \\
\hline & Phytoene & $\zeta$-Carotene & $\beta$-Carotene & \\
\hline Rhodobacter (membranes) & 4890 & 2401 & ND & $32 \cdot 9$ \\
\hline Anabaena (membranes) & 2238 & 102 & 1535 & $42 \cdot 2$ \\
\hline $\begin{array}{l}\text { Synechocystis } \\
\text { (membranes) }\end{array}$ & 1355 & 356 & 2079 & $64 \cdot 2$ \\
\hline $\begin{array}{l}\text { Synechocystis } \\
\text { (purified thylakoids) }\end{array}$ & 1332 & 1445 & 384 & $57 \cdot 9$ \\
\hline
\end{tabular}

ND, Not detectable.

ene, in vitro formation up to $\zeta$-carotene was possible. In all cases, the in vitro reaction sequence included the phytoene desaturation step. The conversion rates for phytoene desaturase were about $30 \%$ for Rhodobacter, $40 \%$ for Anabaena, and about $60 \%$ for Synechocystis. Thylakoids from Synechocystis were purified from the outer membranes and from cytoplasmic contamination by sucrose density-gradient centrifugation. These purified thylakoids showed comparable in vitro formation of phytoene and especially $\zeta$-carotene, with less incorpora- tion of radioactivity into $\beta$-carotene. The conversion rate (phytoene to $\zeta$-carotene) for phytoene desaturase was similar to that of the crude membrane preparation. This result clearly demonstrates the association of phytoene desaturase with the thylakoids and supports the immunogold-localization studies. The impaired conversion of $\zeta$ carotene to $\beta$-carotene is certainly due to a partial damage of membrane integrity caused by the hypotonic sucrose solutions during density-gradient centrifugation.

The high lipophilicity of the substrates and products of 
carotene-converting enzymes imply that phytoene desaturase might be membrane-associated. There has been no previous attempt to determine the subcellular localization of carotenogenic enzymes, due to the lack of suitable antibodies. Indications that phytoene desaturase is a membrane protein were obtained by solubilization studies with crude membrane preparations from Synechocystis (Bramley \& Sandmann, 1987). Our immunogold-localization studies together with the in vitro data clearly indicate that phytoene desaturase might be exclusively localized in photosynthetic membranes of prokaryotic photosynthetic organisms.

This work was supported by the Deutsche Forschungsgemeinschaft. AS. was the recipient of a Research Fellowship of the Alexander von Humboldt Foundation (Bonn, FRG) for a leave to the University of Konstanz. The authors thank Professor Dr W. Rathmayer for providing electron microscopy facilities and Professor Dr P. Böger for helpful discussions.

\section{References}

Armstrong, G. A., Alberti, M., Leach, F. \& Hearst, J. E. (1989). Nucleotide sequence, organization, and nature of the protein products of the carotenoid biosynthesis gene cluster of Rhodobacter capsulatus. Molecular and General Genetics 216, 254-268.

Bartley, G. E. \& Scolnik, P. A. (1989). Carotenoid biosynthesis in photosynthetic bacteria. Journal of Biological Chemistry 264, 13109-13113.

Bergmann, B., Lindblad, P., Pettersson, A., Renström, E. \& TIBERG, E. (1985). Immuno-gold localization of glutamine synthetase in a nitrogen-fixing cyanobacterium (Anabaena cylindrica). Planta 166, 329-334.
Bramley, P. M. (1985). The in vitro biosynthesis of carotenoids. Advances in Lipid Research 21, 243-279.

Bramley, P. M. \& Davies, B. H. (1976). $\beta$-Carotene biosynthesis by extracts of the $\mathrm{C} 115$ mutant of Phycomyces blakesleeanus. Phytochemistry 15, 1913-1916.

Bramley, P. M. \& Sandmann, G. (1987). The solubilisation of carotenogenic enzymes of Aphanocapsa. Phytochemistry 26, $1935-1939$.

Clarke, I. E., Sandmann, G., Bramley, P. M. \& Böger, P. (1982). Carotene biosynthesis with isolated photosynthetic membranes. FEBS Letters 140, 203-206.

Hawthornthwaite, A. M., Lanaras, T. \& Codd, G. A. (1985). Immunoelectron microscopy localization of Calvin cycle enzymes in Chlorogleopsis fritschii. Journal of General Microbiology 131, 2497-2500.

MARRS, B. (1981). Mobilization of the genes for photosynthesis from Rhodopseudomonas capsulata by a promiscuous plasmid. Journal of Bacteriology 146, 1003-1012.

Murata, N. \& Omata, T. (1988). Isolation of cyanobacterial plasma membranes. Methods in Enzymology 167, 245-251.

ReYNOLDS, E. S. (1963). The use of lead citrate at high $\mathrm{pH}$ as an electron-opaque stain in electron microscopy. Journal of Cell Biology 17, 208-213.

Rohde, M., Mayer, M., Dutscho, R., Wohlfarth, G. \& Buckel, W. (1988). Immunocytochemical localization of two key enzymes of the 2-hydroxyglutarate pathway of glutamate fermentation in Acidaminococcus fermentans. Archives of Microbiology 150, 504-508.

SANDMANN, G. \& BÖGER, P. (1989). Inhibition of carotenoid biosynthesis by herbicides. In Target Sites of Herbicide Action, pp. 25-44. Edited by P. Böger \& G. Sandmann. Boca Raton: CRC Press.

SandmanN, G. \& KowalCzYK, S. (1989). In vitro carotenogenesis and characterization of the phytoene desaturase reaction in Anacystis. Biochemical and Biophysical Research Communications 163, 916-921.

Schmidt, A., Sandmann, G., Armstrong, G. A., Hearst, J. E. \& BöGER, P. (1989). Immunological detection of phytoene desaturase in algae and higher plants using an antiserum raised against a bacterial fusion-gene construct. European Journal of Biochemistry 184, 375-378. 